\title{
An Assessment of the Deterioration of Fabricated Metal Thread with Light, and Temperature and Humidity Factors: A Focused Study of Asian Textile Collections at the Metropolitan Museum of Art, New York
}

\author{
Hae Jin Park | Minsun Hwang ${ }^{1}$ | Yong Jae Chung* \\ Department of Textile Conservation, The Metropolitan Museum of Art, New York, 10028, United States \\ *Department of Heritage Conservation and Restoration, Graduate School of Cultural Heritage, \\ Korea National University of Cultural Heritage, Buyeo, 33115, Korea \\ ${ }^{1}$ Corresponding Author: MinSun.Hwang@metmuseum.org, +1-212-650-2465
}

\begin{abstract}
To investigate the deterioration of textiles with metal thread, I surveyed 40 textile objects, dating from the 11th to the 19th century from Korea, China, Japan, and Central Asia at the Metropolitan Museum of Art, New York. This survey included various types, widths, and thicknesses of metal thread. In addition, deterioration was examined under the microscope and color information was collected using the spectrophotometer. While investigating metal thread in the collections, I fabricated 12 different types of metal samples with metal leaf( $24 \mathrm{~K}$ gold, silver, and copper leaf), adhesive (hide animal glue and a mixture of hide animal glue and iron oxide red), and paper substrate(Korean mulberry and Taiwanese kozo paper). The accelerated deterioration process of those fabricated samples was carried out using a light box(UV and daylight), and a humidity cabinet. In the light experiment with blue scales textile fading card(aka, blue wool standard), the metal leaf began to peel off during the deterioration process with 756,000 lux-hours UV and daylight. In the temperature and humidity experiment, I could observe the reddish tarnish on copper, and some part of it began to peel off. Color reading on the light exposed samples showed that the degree of color change on the surface follows the amount of exposure as it increased over time. On the other hand, color change on the samples after artificial deterioration using temperature and humidity factors showed random change of color with occasional spikes. Distortion of original shape worsened in the samples exposed to temperature and humidity.
\end{abstract}

Key Words: Textiles, Metal thread, Deterioration, Light, Temperature and humidity

\section{INTRODUCTION}

Textiles play important roles in human life not only to serve the functional purpose of providing protection, but beyond the practical uses, also to represent the wearer's social status and position as a means of indicating the person's rank and/or wealth. People have decorated textiles in many ways with patterns, weaving techniques, dyeing or painting, and embroidery. Among these purposes, metal thread is known as one of the luxurious materials used in religious and secular cultures, either interwoven in the fabrics or used to highlight parts of silk embroidery.
According to established research on metal thread types, one research classifies the metal thread with "....metal wires or of strips wrapped around a core of vegetable or animal fiber yarns."'(Tímár-Balázsy and Eastop, 1998). Another investigation describes five categories of metal thread: "(1) metal applied with adhesive to already woven fabrics, (2) metal wire or flattened strip, (3) metal wire or strips wound around fiber core, (4) metallic surface applied with adhesive to organic wrapping wound around fiber core, and (5) metallic surface applied with adhesive to cellulosic or proteinaceous strips"(Indictor et al., 1989). Analytical studies of the materials of metal 
thread have also been conducted using the high-powered microscope, atomic emission spectrographic analysis, X-ray fluorescence spectroscopy(XRF), and scanning electron microscopic energy dispersive X-ray analysis(SEM-EDS) (Indictor et al., 1988; Nord and Tronner, 2000; Muros et al., 2007; Jeong et al., 2013; Yu et al., 2014).

In this study, the scope of my research will include three steps: (1) investigation of the textile collection with metal thread, (2) fabrication of metal thread, and (3) artificial deterioration with environmental factors. Investigating 40 textile objects, dating from the 11th to the 19th century from Korea, China, Japan, and Central Asia at the Metropolitan Museum of Art(The Met), New York, I was able to identify and document the surface condition of the selected textile objects which have been exhibited and stored in museum environments. After I observed the condition of the textile objects, I realized the understanding the degradation process and conservation environment plays important roles for better preservation and future conservation treatment of the historic museum objects with metal thread. For historic textile, light is one of the main environmental factors contributing to the degradation process. Temperature and humidity also play important roles for Korean archaeological textiles with metal thread and their condition. Therefore, I fabricated 12 different types of metal samples glued onto paper substrate and had them undergo the artificial deterioration process with light(UV and daylight), and again separately with temperature and humidity.

\section{MATERIALS AND METHODS}

\subsection{Investigation of the textile collections with metal thread}

For investigation of the textile objects with metal thread, 40 textiles and costumes were selected dating from the 11 th to the 19th century, with origins in Korea, China, Japan and Central Asia(Figure 1). This survey included thread types, width, and thickness of metal threads. In addition, deterioration was examined under the microscope (Axio Zoom, V16, ZEISS, Germany) while color information

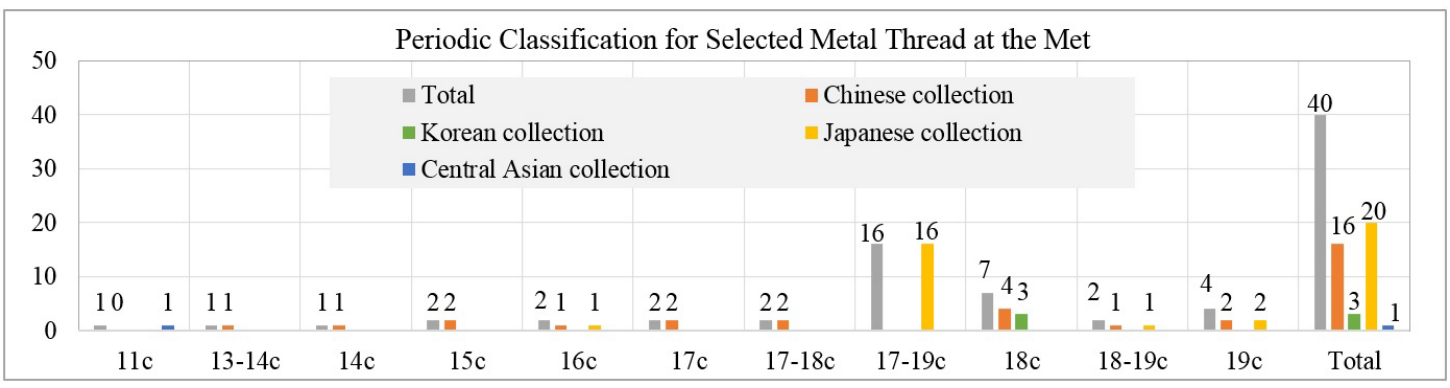

Figure 1. Periodic classification of selected textile collections with metal thread at the Metropolitan Museum of Art(The Met), New York.

Table 1. Used materials for the fabrication of metal thread

\begin{tabular}{|c|c|c|c|}
\hline No. & & Materials & Details \\
\hline \multirow{3}{*}{1} & \multirow{3}{*}{ Metal leaf } & Gold & Detected elements : $\mathrm{Au}, \mathrm{Ca}, \mathrm{Fe}$ \\
\hline & & Silver & Detected elements : $\mathrm{Ag}, \mathrm{Ca}, \mathrm{Fe}$ \\
\hline & & Copper & Detected elements : $\mathrm{Cu}, \mathrm{Ca}, \mathrm{Fe}$ \\
\hline \multirow{2}{*}{2} & \multirow{2}{*}{ Substrate } & Korean mulberry paper & Weight : $50.34 \mathrm{~g} / \mathrm{m}^{2}$, Thickness : $0.15 \mathrm{~mm}$ \\
\hline & & Taiwanese kozo paper & Weight : $26.00 \mathrm{~g} / \mathrm{m}^{2}$, Thickness : $0.08 \mathrm{~mm}$ \\
\hline \multirow{2}{*}{3} & \multirow{2}{*}{ Adhesive } & Ground hide glue & - \\
\hline & & Mixture of ground hide glue and iron oxide red & - \\
\hline
\end{tabular}


was collected using the spectrophotometer(CM-2600d, KONICA MINOLTA, Japan).

\subsection{Fabrication of metal thread}

I fabricated metal thread for the artificial deterioration experiment based on each textile. I purchased three different types of metal leaf: $24 \mathrm{~K}$ gold, silver, and copper from Barnabas Blattgold Company. XRF element analysis showed that the purchased metal leaf contains $\mathrm{Ca}$ and $\mathrm{Fe}$ in addition to $\mathrm{Au}, \mathrm{Ag}$ and $\mathrm{Cu}$ components. For the substrate, I used the Korean mulberry paper crafted at the Korean representative traditional paper store, Janggibang, and Taiwanese kozo paper purchased from a Taipei city traditional paper store, Fu Lung Cotton Paper Co., LTD (Table 1). Prior to the adhesive application, I conducted the sizing treatment on all the paper substrates with $3 \%$ $(\mathrm{w} / \mathrm{w})$ ground hide glue and $0.2 \%(\mathrm{w} / \mathrm{w})$ alum on the Plexiglas sheet(Figure 2). Next, under higher temperature than $63^{\circ} \mathrm{C}$, the physical properties of animal glue can be changed and lost their adhesive strength so I had to make sure this process was under adequate temperature and double boilers. I heated adhesive solution in double boiler under $63^{\circ} \mathrm{C}$ and applied two different adhesive solutions to the sized paper substrate: $10 \%(\mathrm{w} / \mathrm{w})$ ground hide glue, purchased from Talas Company, and mixture of $10 \%(\mathrm{w} / \mathrm{w})$ ground hide glue and $1.5 \%(\mathrm{w} / \mathrm{w})$ iron oxide red. After placing the metal leaf on the surface of the papers, I brushed to create the initial contact between the metal leaf and papers, and then used a glass pestle to transfer it permanently(Figures 3, 4). These fabricated metal thread samples were labeled as Table 2.

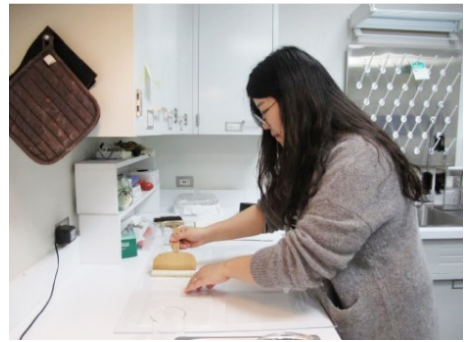

Figure 2. Sizing treatment process of the paper substrate.

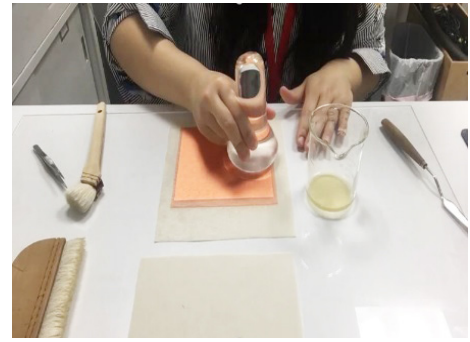

Figure 3. Application of the glass pestle for the permanent transfer.

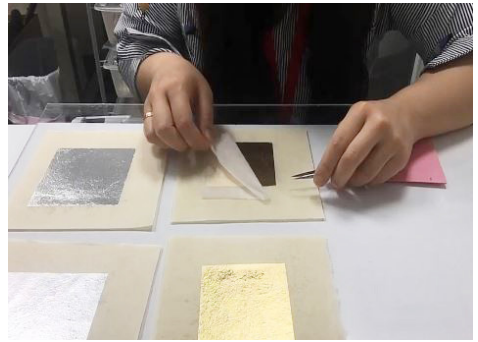

Figure 4. Application of the adhesive with metal leaf on paper substrate.

Table 2. Lists of fabricated metal thread samples

\begin{tabular}{|c|c|c|c|c|}
\hline No. & Substrate & Adhesive & Metal leaf & Sample label \\
\hline 1 & \multirow{7}{*}{ Korean mulberry paper } & \multirow{3}{*}{ Ground hide glue } & Gold & A \\
\hline 2 & & & Silver & B \\
\hline 3 & & & Copper & $\mathrm{C}$ \\
\hline 4 & & \multirow{3}{*}{$\begin{array}{l}\text { Mixture of ground hide glue } \\
\text { and iron oxide red }\end{array}$} & Gold & $\mathrm{D}$ \\
\hline 5 & & & Silver & $\mathrm{E}$ \\
\hline 6 & & & Copper & $\mathrm{F}$ \\
\hline 7 & & - & - & KP \\
\hline 8 & \multirow{7}{*}{ Taiwanese kozo paper } & \multirow{3}{*}{ Ground hide glue } & Gold & G \\
\hline 9 & & & Silver & $\mathrm{H}$ \\
\hline 10 & & & Copper & I \\
\hline 11 & & \multirow{3}{*}{$\begin{array}{l}\text { Mixture of ground hide glue } \\
\text { and iron oxide red }\end{array}$} & Gold & $\mathrm{J}$ \\
\hline 12 & & & Silver & $\mathrm{K}$ \\
\hline 13 & & & Copper & $\mathrm{L}$ \\
\hline 14 & & - & - & $\mathrm{TP}$ \\
\hline
\end{tabular}


Table 3. Deterioration condition for light exposure

\begin{tabular}{|c|c|c|c|c|}
\hline No. & Light source & Exposure condition & Exposure time & Exposure quantity \\
\hline 1 & \multirow{4}{*}{$\begin{array}{c}\text { UV } \\
\stackrel{+}{+} \\
\text { Daylight }\end{array}$} & \multirow{4}{*}{$\begin{array}{c}1028 \mathrm{UV} \mu \mathrm{w} / \mathrm{Lumen}^{2} \\
3238 \mathrm{~mW} / \mathrm{M}^{2} \\
3150 \mathrm{lux}\end{array}$} & 56 hours & 176,400 lux-hours \\
\hline 2 & & & 112 hours & 352,800 lux-hours \\
\hline 3 & & & 168 hours & 529,200 lux-hours \\
\hline 4 & & & 240 hours & 756,000 lux-hours \\
\hline
\end{tabular}
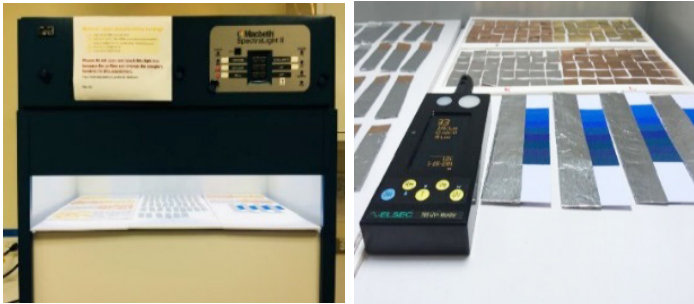

Figure 5. Light box and blue scales textile fading cards.

\subsection{Artificial deterioration with environment factors}

\subsubsection{Light(UV and daylight)}

The light deterioration experiment was conducted in the light box(SpectraLight II, Macbeth, China) under both UV and daylight(Table 3). To achieve an accurate measurement of light exposure, aluminum foil was used to cover and control the exposed area of the samples. During the light exposure with UV and daylight, the blue scales textile fading cards, purchased at Gaylord Archival, were put together with fabricated metal samples to check light fastness(Figure 5). The blue scales textile fading cards consist of eight synthetic dyes with varied light fastness and were labeled blue \#1 to blue \#8 for this research. Daily average temperature and humidity inside the light box were measured as $30.58^{\circ} \mathrm{C}$ and $34.06 \%$; highest temperature and humidity were $46.83{ }^{\circ} \mathrm{C}$ and $47.20 \%$; and lowest were measured as $22.56^{\circ} \mathrm{C}$ and $12.23 \%$.

Before and after light exposure, the surface was examined under the microscope(Axio Zoom, V16, ZEISS, Germany), a Camera(G10, Cannon, Japan), and high-quality scanner (Expression 10000XL, EPSON, Japan); color change was recorded with the spectrophotometer(CM-2600d, KONICA MINOLTA, Japan).

\subsubsection{Temperature and humidity}

To simulate the temperature and humidity factors,

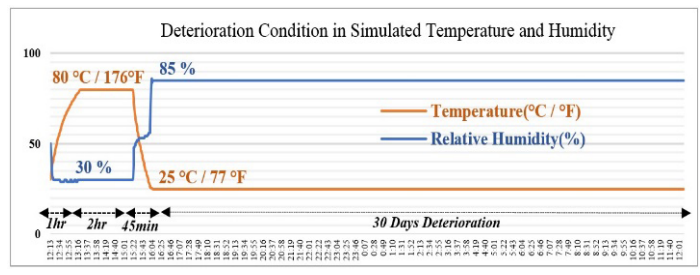

Figure 6. Deterioration condition with temperature and humidity.
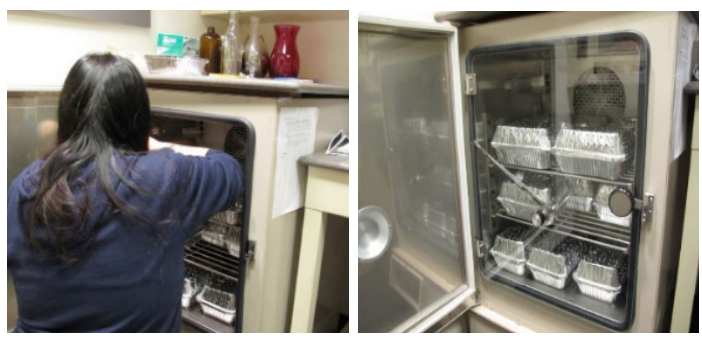

Figure 7. Humidity cabinet.

which had affected the Korean archaeological textiles, I would like to explain the unique burial process, taking place during the Joseon dynasty in Korea. Koreans followed a burial procedure using calcium oxide or lime mortar and then upon burial, lime harden and coffin temperature rises, sterilizing everything inside. As the temperature drops to a low degree, the coffin becomes a humid environment due to the human body and textiles remaining moist. All of these chemical reactions results in the final step of this burial process creating a hermetically sealed coffin.

The temperature and humidity experiment was carried out in the humidity cabinet(LHL-112M, ESPEC CROP, Japan). I modified the temperature and humidity condition for the deterioration experiment with fabricated metal samples following the temperature and humidity study of the Korean burial culture using calcium oxide, lime mortar (National Research Institute of Cultural Heritage, 2010; 2011). The fabricated metal samples were placed in the 


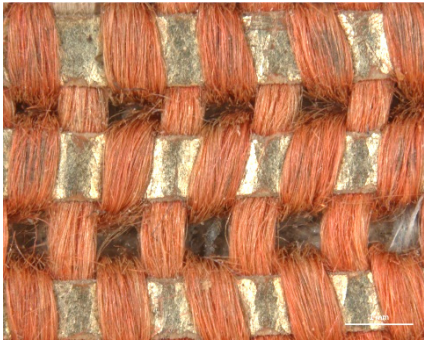

Figure 8. Metal foil on a paper substrate $(\times 20)$, rank badge with lion, 15C, China, 1988.154.1.

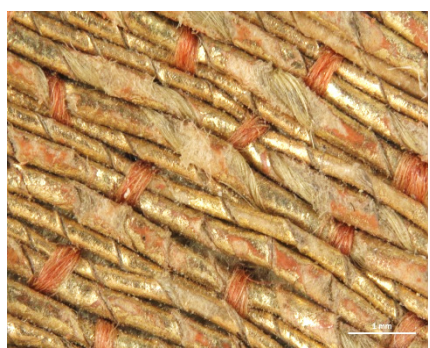

Figure 11. Metal foil on a paper substrate around a silk core $(\times 20)$, rank badge with lion, 15C, China, 1988. 154.1.

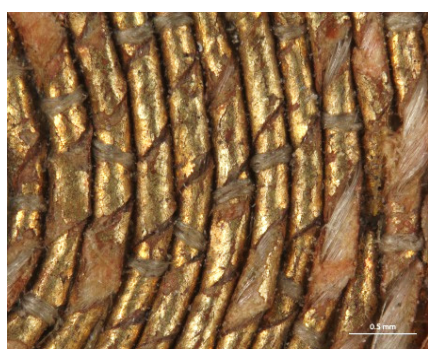

Figure 14. Metal foil on a paper substrate around a silk core $(\times 40)$, rank badge with a pair of tiger-leopards, 18C, Korea, 51.40.

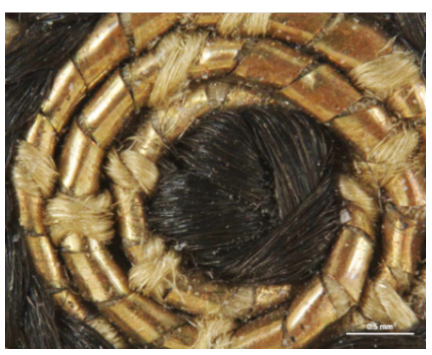

Figure 17. Metal strip around a silk core $(\times 40)$, rank badge with a Crane, 18C, Korea, 53.60.19.

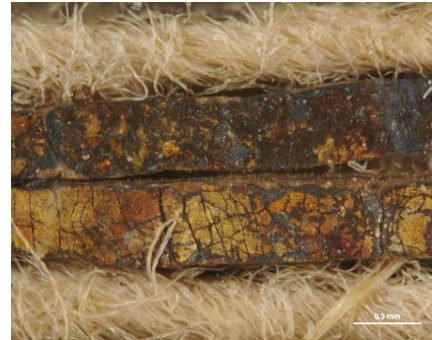

Figure 9. Metal foil on a leather substrate $(\times 40)$, piece, $11 \mathrm{C}$, Central Asia, 24.166.33.

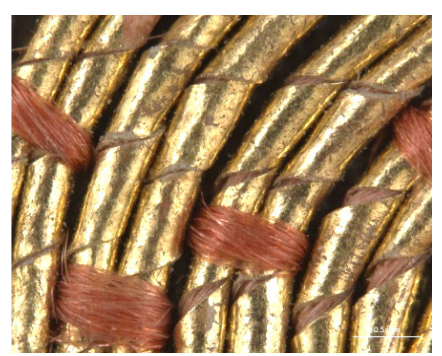

Figure 12. Metal foil on a paper substrate around a silk core $(\times 40)$, rank badge, 19C, China, 46.133.2.

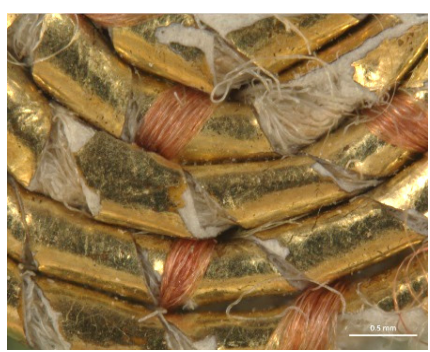

Figure 15. Metal foil on a paper substrate around a silk core $(\times 40)$, piece from a Kosode, 17-19C, Japan, 2008. 335.37.

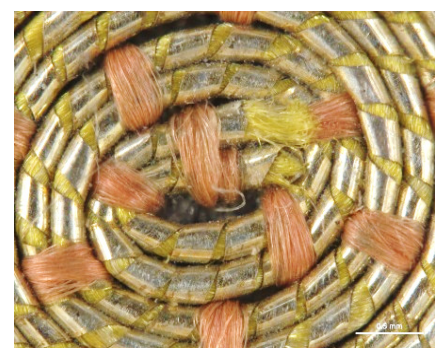

Figure 18. Metal strip around a silk core $(\times 40)$, rank badge with a crane, 18C, China, 46.133.45.

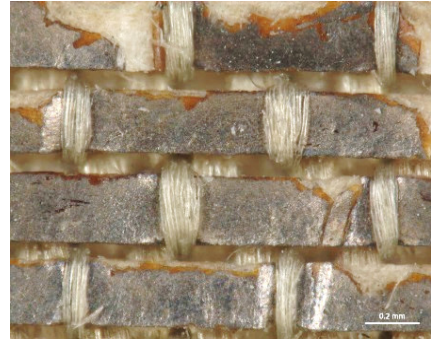

Figure 10. Metal foil on a paper substrate $(\times 80)$, man's trousers, $19 \mathrm{C}$, Japan, 09.188.

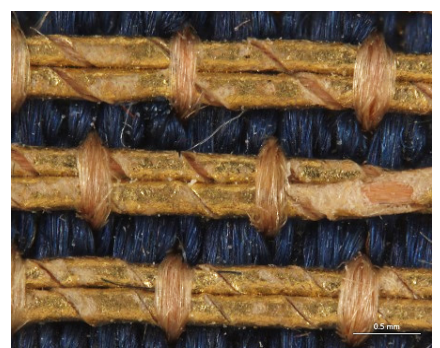

Figure 13. Metal foil on a paper substrate around a silk core $(\times 40)$, velvet textile for a dragon robe, $17 \mathrm{C}$, China, 1987.147.

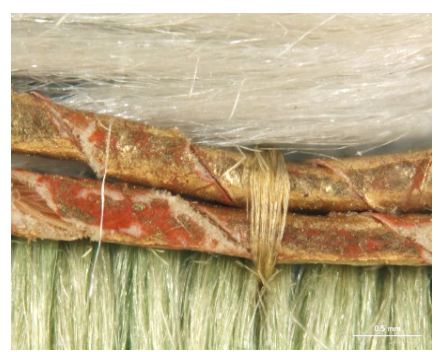

Figure 16. Metal foil on a paper substrate around a silk core $(\times 40)$, theatrical robe for the role of a guard, 18C, China, 30.76.33.

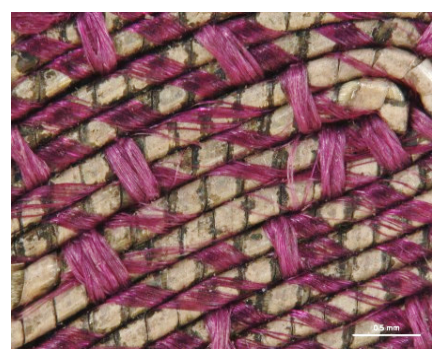

Figure 19. Metal strip around a silk core $(\times 40)$, rank badge with manchurian crane, 19C, China, 30.75.877. 
humidity cabinet, which had been set to $80^{\circ} \mathrm{C}$ and $30 \%$ humidity and would hold that condition for 2 hours. I next adjusted the temperature down to $25^{\circ} \mathrm{C}$ and raised the humidity up to $85 \%$ and then set the conditions to be preserved for the next 30 days(Figures 6, 7).

The surface was again examined before and after temperature and humidity experiment under the microscope (Axio Zoom, V16, ZEISS, Germany) with a camera(G10, CANNON, Japan) and high-quality scanner(Expression 10000XL, EPSON, Japan) and color change was recorded with the spectrophotometer(CM-2600d, Konica Minolta, Japan).

\section{RESULTS}

\subsection{Metal thread types and their condition in the Met's textile collection}

3.1.1. Classification of metal thread types in the Met's textile collection

In my opinion, metal thread can be categorized into five different types. The first type is the metal foil on either a paper or animal leather substrate, laid flat and woven onto the fabric. The second type is the metal foil on a substrate around a silk or cotton core. The third type is the metal strip around a silk or cotton core. The fourth type is a solid metal wire, and the last is the solid metal wire wrapped tightly around silk or cotton. Investigation of 40 selected textiles detected only the first three types of metal threads with various widths and thicknesses (Figures 8 19).

3.1.2. Condition of metal thread in the Met's textile collection

Examination of metal thread included study of the condition due to its deterioration as well as related to thread type, width and thickness, and color information as one can see in Table 4. I was able to identify the deterioration condition in four categories: cracking, corrosion and tarnish, dirt, and abrasion. First, 'cracking' is the decomposition and breakdown without any separation of its parts. Second, 'corrosion and tarnish' is the discoloration and chemical reaction of metal. Third, 'dirt' is various substances combined with solid particles sitting and accumulating on the surface. And last, 'abrasion' is the mechanical wearing away of surface.

\subsection{Deterioration with light(UV and daylight)}

\subsubsection{Color analysis}

The entire deterioration process with UV and daylight included the exposure of blue scales textile fading cards and metal samples for a total 756,000 lux-hours. Each color of the blue scales textile fading cards and the metal samples was analyzed with spectrophotometer before and after the light exposure to check the effect. After 176,400 lux-hours of light exposure, color change was visibly noticeable on the blue $\# 1$, \#2, and \#3(Table 5). It is known that blue \#1 is very poorly resistant to light and blue \#8 has excellent resistance to light. Twice the exposure time is required to achieve a similar degree of fading on blue $\# 2$ as on blue $\# 1$, and the same formula applies to blue \#3 as well. The color reading of blue \#1 to \#3 from my experiment followed the light fastness pattern as described; however, the others colors(blue \#4 to blue \#8) in the same environment did not follow the fading pattern and reaction rate(Figure 20).

In the $\mathrm{L}^{*}, \mathrm{a}^{*}$ and $\mathrm{b}^{*}$ color space, $\mathrm{L}$ indicates lightness, and $\mathrm{a}^{*}$ and $\mathrm{b}^{*}$ are the chromaticity coordinates: $+\mathrm{a}^{*}$ is the red direction, $-\mathrm{a}^{*}$ is the green direction, $+\mathrm{b}^{*}$ is the yellow direction, and $-b^{*}$ is the blue direction. The result of my light experiment showed that the blue color started to fade and the $b^{*}$ values increased on the blue \#1, \#2, and $\# 3$, moving toward $+b^{*}$ direction as the amount of light exposure accumulated. The reading of the spectrophotometer with the D65-10 ${ }^{\circ}$ source indicated the difference of the $\mathrm{b}^{*}$ value on the blue $\# 1$, exposed for 176,400 lux-hours, increasing to 12.5 . When the blue \#1 was exposed for 756,000 lux-hours, the difference of the $b^{*}$ value became 23.6 toward $+b^{*}$ space. The $b^{*}$ reaction rate on the blues $\# 1$, \#2 and \#3 was initially changing quickly until it hit 176,400 lux-hours: afterwards the reaction rate slowed down with the $b^{*}$ value still steadily increasing(Figure 21 ).

The color change pertaining to the $\triangle E^{*}$ ab value on the fabricated metal samples showed that the surface 
Table 4. Deterioration condition classification with thread type, width and thickness, and color at the Met's collections

\begin{tabular}{|c|c|c|c|c|c|c|c|c|c|c|c|c|}
\hline \multirow{2}{*}{ No. } & \multirow{2}{*}{ Condition } & \multirow{2}{*}{$\begin{array}{l}\text { Object name } \\
\text { (Accession } \\
\text { No.) }\end{array}$} & \multirow{2}{*}{$\begin{array}{c}\text { Period } \\
\text { (Country) }\end{array}$} & \multirow{2}{*}{$\begin{array}{l}\text { Microscopic } \\
\text { image }(\times 40)\end{array}$} & \multirow{2}{*}{$\begin{array}{l}\text { Thread type } \\
\text { (width/ } \\
\text { thickness) } \\
(\mathrm{mm})\end{array}$} & \multicolumn{7}{|c|}{ Color information } \\
\hline & & & & & & $\begin{array}{l}\text { Light } \\
\text { source }\end{array}$ & $\mathrm{L}^{*}$ & $a^{*}$ & $b^{*}$ & $\mathrm{C}^{*}$ & $h^{\circ}$ & Color \\
\hline \multirow{3}{*}{1} & \multirow{6}{*}{ Cracking } & \multirow{3}{*}{$\begin{array}{c}\text { Piece from } \\
\text { a summer } \\
(2008.335 .48)\end{array}$} & \multirow{3}{*}{$\begin{array}{l}\text { 17-19C } \\
\text { (Japan) }\end{array}$} & & \multirow{3}{*}{$\begin{array}{c}\text { Metal foil } \\
\text { on a paper } \\
\text { substrate } \\
\text { around a } \\
\text { silk core } \\
(1.065 / \\
0.468)\end{array}$} & D $65-10^{\circ}$ & 52.58 & 7.92 & 30.74 & 31.75 & 75.55 & \\
\hline & & & & & & $\mathrm{A}-10^{\circ}$ & 55.11 & 12.16 & 33.40 & 35.55 & 70.00 & \\
\hline & & & & & & $\mathrm{CWF}-10^{\circ}$ & 54.25 & 5.02 & 34.60 & 34.96 & 81.74 & \\
\hline \multirow{3}{*}{2} & & \multirow{3}{*}{$\begin{array}{c}\text { Piece } \\
(2008.335 .63)\end{array}$} & \multirow{3}{*}{$\begin{array}{l}\text { 17-19C } \\
\text { (Japan) }\end{array}$} & & \multirow{3}{*}{$\begin{array}{c}\text { Metal foil } \\
\text { on a paper } \\
\text { substrate } \\
(0.543 / \\
0.543)\end{array}$} & D $65-10^{\circ}$ & 56.09 & 6.53 & 27.31 & 28.08 & 75.56 & \\
\hline & & & & & & $\mathrm{A}-10^{\circ}$ & 58.35 & 10.93 & 29.55 & 31.50 & 69.71 & \\
\hline & & & & & & CWF-10 $10^{\circ}$ & 57.53 & 4.10 & 30.88 & 31.16 & 82.44 & \\
\hline \multirow{3}{*}{3} & \multirow{6}{*}{$\begin{array}{l}\text { Corrosion } \\
\text { and tarnish }\end{array}$} & \multirow{3}{*}{$\begin{array}{c}\text { Piece } \\
(24.166 .33)\end{array}$} & \multirow{3}{*}{$\begin{array}{c}11 \mathrm{C} \\
\text { (Central } \\
\text { Asia) }\end{array}$} & & \multirow{3}{*}{$\begin{array}{c}\text { Metal foil } \\
\text { on a leather } \\
\text { substrate } \\
(0.576 / \\
0.576)\end{array}$} & D $65-10^{\circ}$ & 43.37 & 5.68 & 17.52 & 18.41 & 72.03 & \\
\hline & & & & & & $\mathrm{A}-10^{\circ}$ & 45.05 & 8.76 & 19.39 & 21.27 & 65.68 & \\
\hline & & & & & & $\mathrm{CWF}-10^{\circ}$ & 44.39 & 3.67 & 19.99 & 20.32 & 79.58 & \\
\hline \multirow{3}{*}{4} & & \multirow{3}{*}{$\begin{array}{c}\text { Rank badge } \\
\text { with phoenixes } \\
(36.65 .31)\end{array}$} & \multirow{3}{*}{$\begin{array}{c}16 \mathrm{C} \\
\text { (China) }\end{array}$} & & \multirow{3}{*}{$\begin{array}{c}\text { Metal foil } \\
\text { on a paper } \\
\text { substrate } \\
\text { around a } \\
\text { silk core } \\
(0.677 \text { / } \\
0.271)\end{array}$} & D65-10 & 43.94 & 12.77 & 21.76 & 25.23 & 59.60 & \\
\hline & & & & & & $\mathrm{A}-10^{\circ}$ & 46.62 & 15.99 & 25.43 & 30.04 & 57.83 & \\
\hline & & & & & & CWF-10 $10^{\circ}$ & 45.29 & 8.78 & 24.75 & 26.26 & 70.48 & \\
\hline \multirow{3}{*}{5} & \multirow{6}{*}{ Dirt } & \multirow{3}{*}{$\begin{array}{l}\text { Rank badges } \\
\text { with lion } \\
(1988.154 .1)\end{array}$} & \multirow{3}{*}{$\begin{array}{c}15 \mathrm{C} \\
\text { (China) }\end{array}$} & & \multirow{3}{*}{$\begin{array}{c}\text { Metal foil } \\
\text { on a paper } \\
\text { substrate } \\
(0.836 / \\
0.836)\end{array}$} & $\mathrm{D} 65-10^{\circ}$ & 37.64 & 13.87 & 20.80 & 25.00 & 56.30 & \\
\hline & & & & & & $\mathrm{A}-10^{\circ}$ & 40.38 & 16.30 & 24.56 & 29.48 & 56.43 & \\
\hline & & & & & & CWF-10 $10^{\circ}$ & 39.17 & 9.66 & 24.11 & 25.97 & 68.17 & \\
\hline & & & & & Metal foil & D $65-10^{\circ}$ & 41.55 & 8.48 & 24.25 & 25.69 & 70.73 & \\
\hline 6 & & $\begin{array}{c}\text { Rank badges } \\
\text { with lion } \\
(1988.154 .1)\end{array}$ & $\begin{array}{c}15 \mathrm{C} \\
\text { (China) }\end{array}$ & & $\begin{array}{l}\text { substrate } \\
\text { around a } \\
\text { silk core }\end{array}$ & $\mathrm{A}-10^{\circ}$ & 43.83 & 11.67 & 26.94 & 29.36 & 66.58 & \\
\hline & & & & & $\begin{array}{c}(1.155 / \\
0.357)\end{array}$ & $\mathrm{CWF}-10^{\circ}$ & 43.02 & 5.51 & 27.57 & 28.11 & 78.70 & \\
\hline & & & & & 1 foil & D $65-10^{\circ}$ & 61.83 & 8.79 & 30.38 & 31.62 & 73.86 & \\
\hline 7 & & $\begin{array}{l}\text { dragon and } \\
\text { phoenixes }\end{array}$ & $\begin{array}{l}13-14 \mathrm{C} \\
\text { (China) }\end{array}$ & & $\begin{array}{l}\text { on a paper } \\
\text { substrate }\end{array}$ & $\mathrm{A}-10^{\circ}$ & 64.51 & 12.42 & 33.72 & 35.94 & 69.78 & \\
\hline & & & & & $0.418)$ & $\mathrm{CWF}-10^{\circ}$ & 63.80 & 5.43 & 34.36 & 34.79 & 81.02 & \\
\hline & & & & & Metal foil & $\mathrm{D} 65-10^{\circ}$ & 35.19 & 7.66 & 18.23 & 19.77 & 67.22 & \\
\hline 8 & & $\begin{array}{l}\text { with a pair of } \\
\text { tiger-leopards }\end{array}$ & $\begin{array}{c}18 \mathrm{C} \\
\text { (Korea) }\end{array}$ & & $\begin{array}{l}\text { substrate } \\
\text { around a }\end{array}$ & $\mathrm{A}-10^{\circ}$ & 37.09 & 10.40 & 20.60 & 23.08 & 63.22 & \\
\hline & & & & & $\begin{array}{c}(0.719) \\
0.258)\end{array}$ & CWF- $10^{\circ}$ & 36.30 & 5.24 & 20.67 & 21.32 & 75.77 & \\
\hline
\end{tabular}


Table 5. Color change of blue scales textile fading card before and after light exposure(UV and daylight)

\begin{tabular}{|c|c|c|c|c|c|c|}
\hline \multicolumn{2}{|c|}{ Light exposure(lux-hours) } & Non exposure & $\begin{array}{c}176,400 \\
\text { lux-hours }\end{array}$ & $\begin{array}{c}352,800 \\
\text { lux-hours }\end{array}$ & $\begin{array}{c}529,200 \\
\text { lux-hours }\end{array}$ & $\begin{array}{c}756,000 \\
\text { lux-hours }\end{array}$ \\
\hline \multirow{8}{*}{$\begin{array}{c}\text { Color change } \\
\text { of blue scales } \\
\text { textile fading } \\
\text { card before } \\
\text { and after } \\
\text { light } \\
\text { exposure }\end{array}$} & Blue \#1 & & & & & \\
\hline & Blue \#2 & & & & & \\
\hline & Blue \#3 & & & & & \\
\hline & Blue \#4 & & & & & \\
\hline & Blue \#5 & & & & & \\
\hline & Blue \#6 & & & & & \\
\hline & Blue \#7 & & & & & \\
\hline & Blue \#8 & & & & & \\
\hline
\end{tabular}

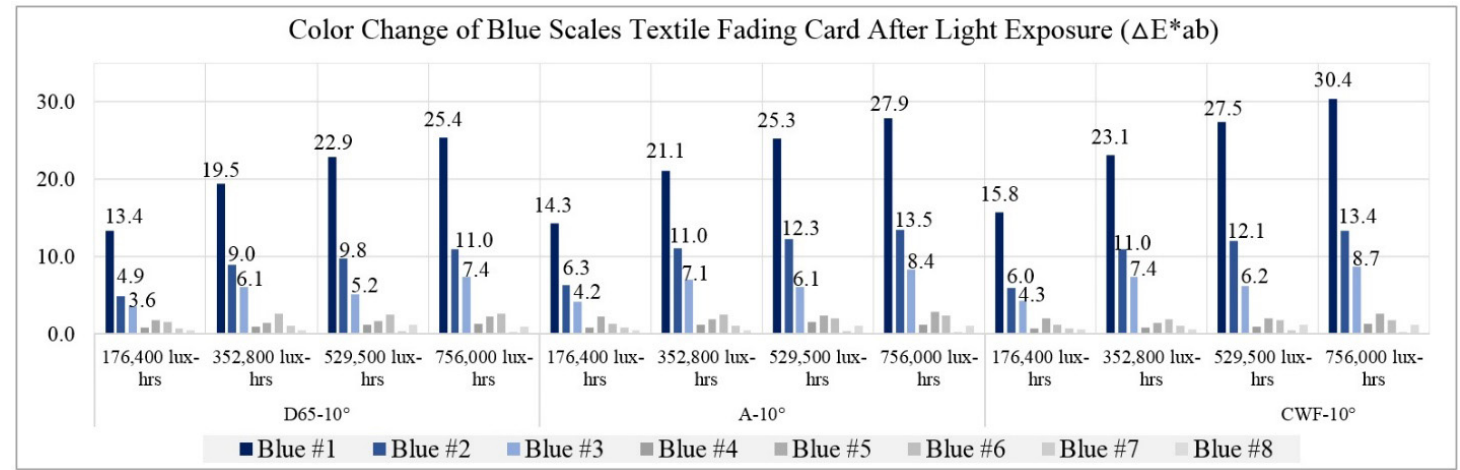

Figure 20. Color change of blue scales textile fading card after light exposure $\left(\triangle \mathrm{E}^{*} \mathrm{ab}\right)$.

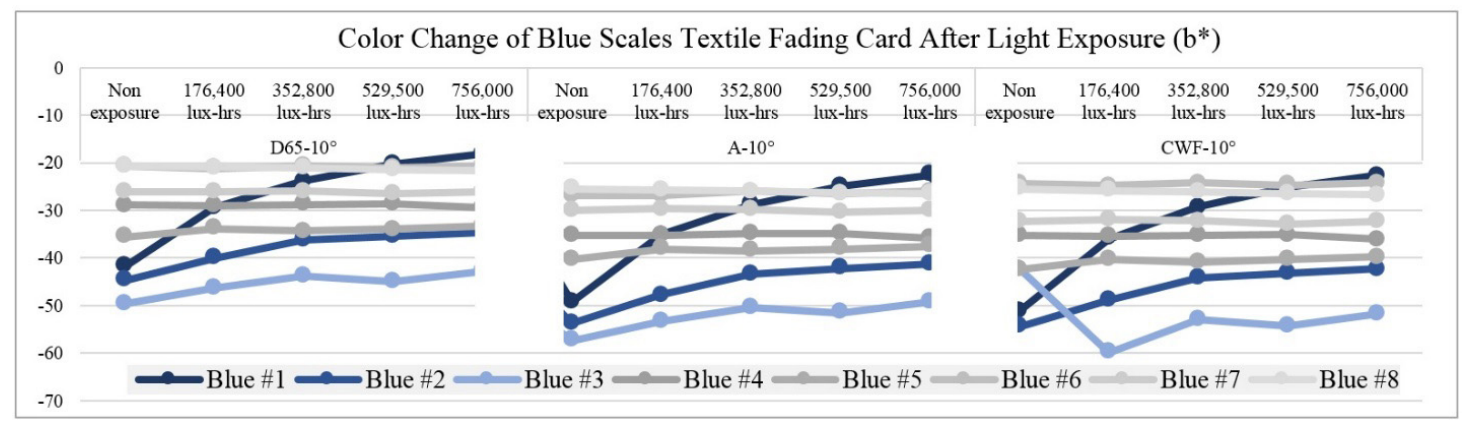

Figure 21. Color change of blue scales textile fading card after light exposure $\left(b^{*}\right)$.

color change followed the amount of light exposure as it increased over time. Among the metal samples made with adhesive and paper, the color change of the copper samples was greater than that of gold and silver. Comparison of the copper samples between $\mathrm{C}$ and F, and between I and $\mathrm{L}$, prepared with two different adhesives and exposed to light for 756,000 lux-hours, showed an interesting outcome: the one with a mixture of animal glue and iron oxide red showed greater color change than the other with animal glue adhesive only. $\mathrm{F}$ and $\mathrm{L}$ samples were made with the same copper leaf and adhesive but on two different paper substrates. However, the result showed the different color changes due to their different thickness and weight properties(Figure 22). 


\subsubsection{Physical change investigation}

The physical changes of the metal, adhesive, and paper can be described as follows: the longer the light exposure, the more physical distortion occurred on the metal samples. When the samples were exposed to light for 756,000 lux-hours, there was no drastic change in the original shape detected by the naked eye, but distortion and peeling off were apparent in some samples under the microscope as seen in Table 6.

\subsection{Deterioration with temperature and humidity}

\subsubsection{Color analysis}

The deterioration process with temperature and humidity

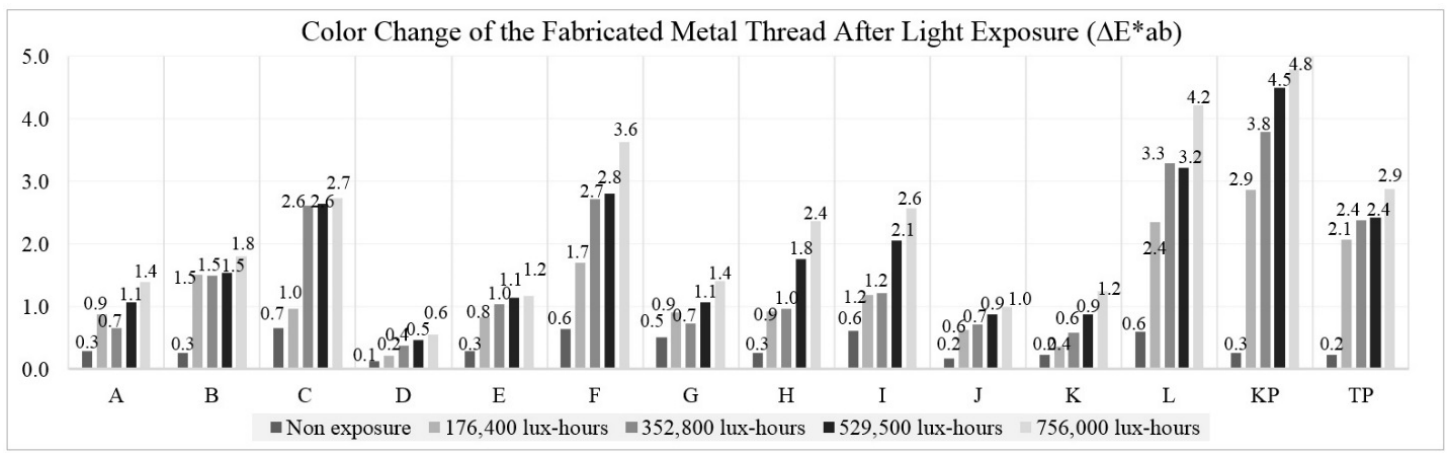

Figure 22. Color change on the surface of fabricated metal samples after the light exposure $\left(\triangle \mathrm{E}^{*} \mathrm{ab}\right)$.

Table 6. Macroscopic and microscopic images after 756,000 lux-hours with UV and daylight

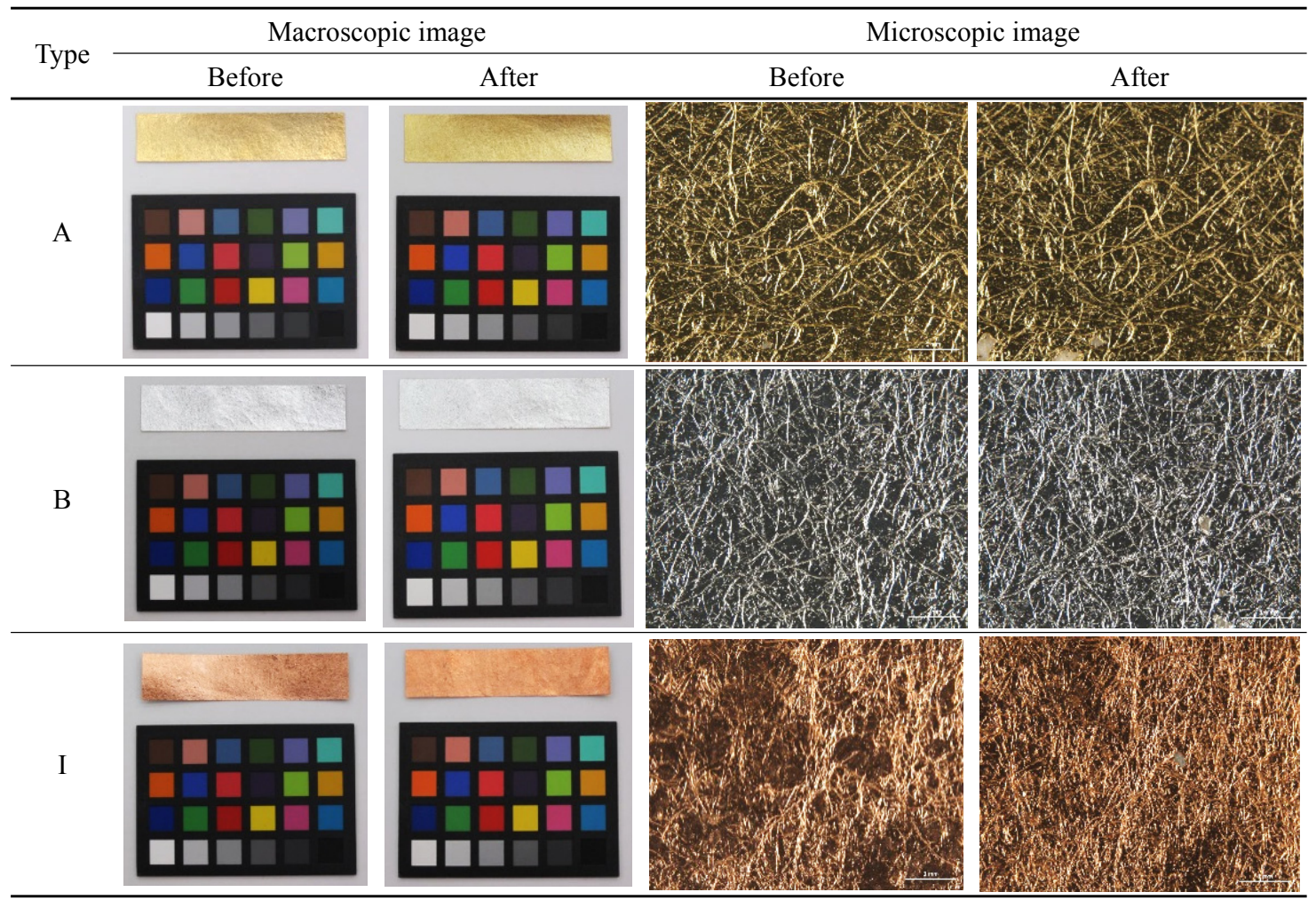




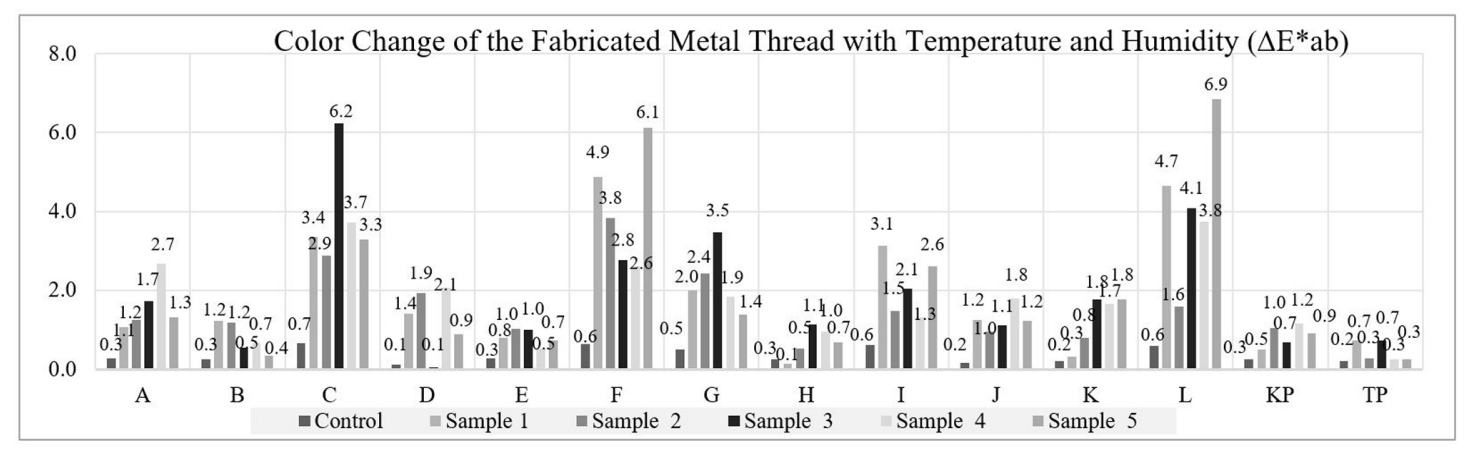

Figure 23. Color change of fabricated metal sample after the deterioration with temperature and humidity $\left(\triangle \mathrm{E}^{*} \mathrm{ab}\right)$.

Table 7. Macroscopic and microscopic images after deterioration with temperature and humidity

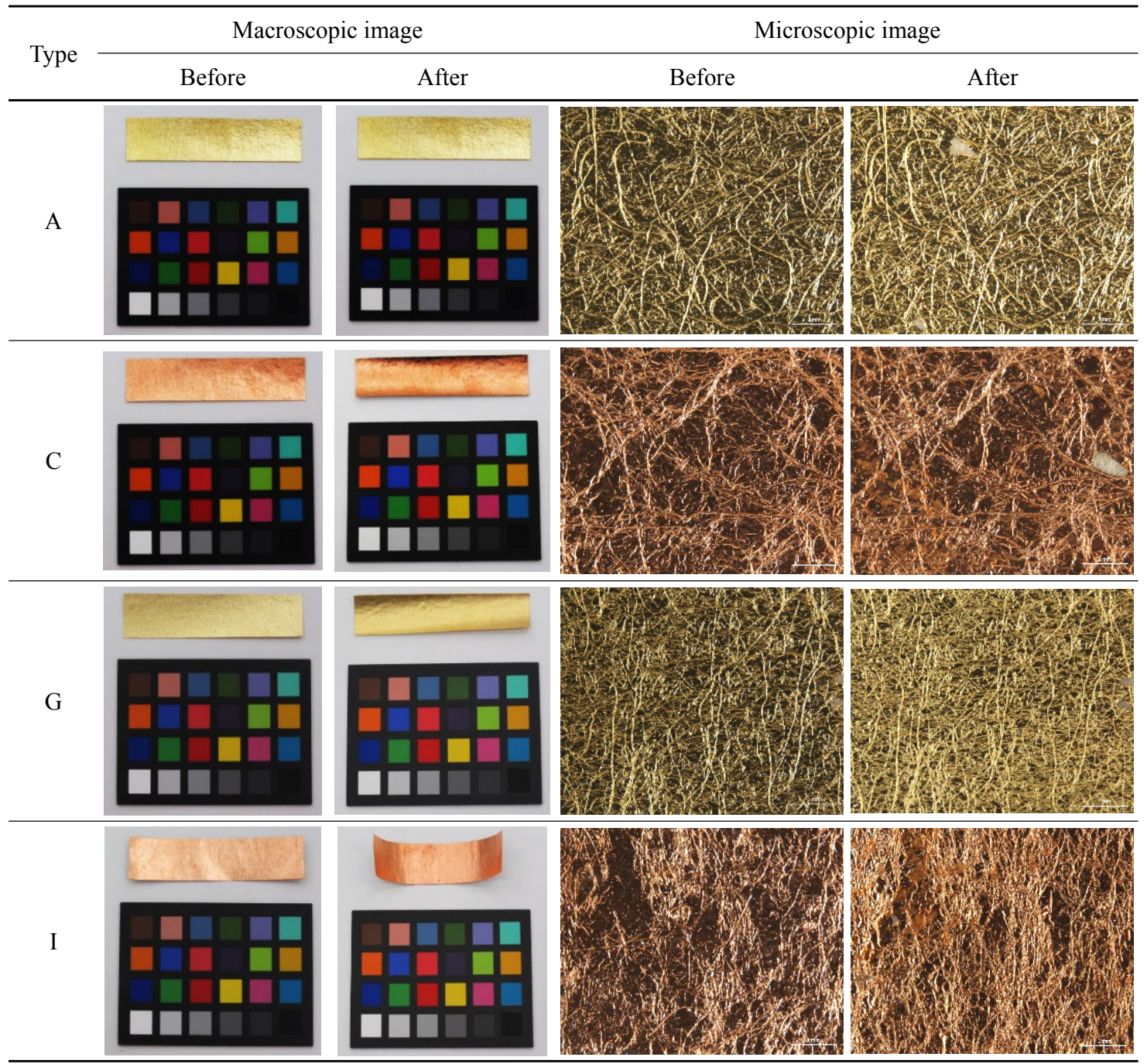


showed the random color change of the $\triangle E^{*}$ ab value on the fabricated metal samples. The average $\triangle E^{*}$ ab values of A, D, G and $\mathrm{J}$ gold samples were shown as 1.6, 1.3, 2.2, and 1.3; those of B, E, H, and $\mathrm{K}$ silver samples were $0.8,0.8,0.7$, and 1.3; and those of C, F, I, and L copper samples were $3.9,4.0,2.1$, and 4.2. This result with $\triangle E^{*}$ ab values showed the color of the gold samples changed to a greater extent than that of the silver samples. Compared to the control samples, the greatest color changes were observed on the copper samples of $\mathrm{C}$, $\mathrm{F}$, and $\mathrm{L}$ as $\triangle \mathrm{E}^{*} \mathrm{ab}$ value of $6.2,6.1$, and 6.9 , and those changes were optically visible as reddish discoloration (Figure 23).

\subsubsection{Physical change investigation}

The deterioration process with temperature and humidity caused dramatic physical change on the metal samples: most samples were twisted and curled up when the experiment ended. Also, the peeling off of the metal leaf as well as exposed paper substrate were observed on the surface of A, C, and I under the microscope(Table 7).

\section{CONCLUSION}

Among the 40 selected textile objects of the Met's textile collection that were investigated, I was able to identify three different types of metal threads: (1) the metal foil on either paper or animal leather, (2) the metal foil on a substrate around silk or cotton core, and (3) the metal strip around silk or cotton core. In addition, I was able to distinguish four categories: cracking, corrosion and tarnish, dirt, and abrasion in the deteriorated conditions of those.

According to the Illuminating Engineering Society of North America, light sensitive materials such as dyed textiles, dyed leathers, or paper are recommended to be exposed to light for a maximum of 125 days per year and 8 hours a day under 50 lux, which adds up to the annual standard 50,000 lux-hours. Harrison, who, in 1954, investigated the daylight intensity in the sky-lighted areas at the Metropolitan Museum of Art, New York, reported that the day-lighted gallery without sun louvers was measured at 1,740 lux, and the one equipped with sun louvers was at 590 lux. He was also able to prove that in the gallery with properly operated sun louvers, it would take 18 years to achieve the same deterioration of the textiles, which were on display in the gallery without any sun louvers for only 6 years(Harrison, 1954).

The outcome of my research on artificial deterioration caused by light exposure with UV and daylight, and the temperature and humidity are as follows: color change of the surface followed the amount of light exposure as it was increased over time during periods of non-exposure, 176,400 lux-hours, 352,800 lux-hours, 529,200 lux-hours, and finally, 756,000 lux-hours. On the other hand, color change with temperature and humidity showed random color changes with occasional spikes in the same sample, but not showing any pattern as was detected in the light deteriorated samples. The metal samples from the temperature and humidity experiment exhibited worse physical deforming, including peeled off metal from the surface and color change, compared to those caused by light exposure. Therefore, temperature and humidity do seem to play a significant role in the conservation environment in comparison to the light factor.

It is said that "Gold is known as a stable inorganic material, however, when it is fabricated and used in very thin leaf form, it can be affected and damaged by various external environmental factors. There is an evidence that high temperature and UV can deteriorate the adhesive layer under the metal leaf and cause to reduce the adhesion so that peeling off and discoloration by the photo-oxide can be caused depending on the air-permeability of the metal leaf"(Yu et al., 2014). In my research, the greatest color changes were observed on the copper samples of $L$ as $\triangle E^{*}$ ab value of 4.2 after light exposure of 756,000 lux-hours. The color change pertaining to the $\triangle E^{*}$ ab value on the fabricated metal samples showed that the surface color change followed the amount of light exposure as it increased over time. Through the physical change investigation, when the samples were exposed to light for 756,000 lux-hours, there was no drastic change 
in the original shape detected by the naked eye, but distortion and peeling off were apparent in some samples under the microscope.

Through the temperature and humidity deterioration, the average $\triangle E^{*}$ ab values of $A, D, G$ and J gold samples were shown as 1.6, 1.3, 2.2, and 1.3; those of B, E, H, and $\mathrm{K}$ silver samples were $0.8,0.8,0.7$, and 1.3. Compared to the control samples, the greatest color changes in temperature and humidity experiment were observed on the copper samples of $\mathrm{C}, \mathrm{F}$, and $\mathrm{L}$ as $\triangle \mathrm{E}^{*}$ ab value of 6.2 , 6.1 , and 6.9, and those changes were optically visible as reddish discoloration. My experiment with temperature and humidity exposure confirmed that the color of gold samples changed to a greater degree than that of the silver samples. Also, it affected the copper samples the most by causing the reddish tarnish and greatest color change on the surface. Reaction rate of color change showed that the materials, used for the fabrication of metal samples, can influence different outcomes.

The materials of the metal thread have different air-permeability, thermal conductivity, flexibility, and hygroscopic properties. For example, the metal leaf was inorganic, paper substrate is porous and hygroscopic, and the animal glue adhesive is water-soluble. Therefore, when those fabricated samples were exposed to different temperature and humidity, it can be predicted that each layer of materials displays different reaction rate.

Historic and archaeological textiles with metal thread have been deteriorated by complex environmental factors for a long time. Hence, I recognized that the environmental conditions and/or materials used for this study were limited for better comparison and more realistic simulation. Also, the outcome of the artificial deterioration experiment with light, and temperature and humidity factors on the metal samples may have been different because the experiment was carried out in a controlled environment, unlike historic and archaeological textiles. Therefore, application of synthetic soiling mixture may need to be added to these experiments to imitate the actual environment, to which historic and archaeological textiles might have been exposed. In addition, further artificial deterioration investigation is needed with different environments, fabrication processes, and materials including various metal alloys and different types of adhesive and paper.

\section{ACKNOWLEDGEMENTS}

Our thanks must go to the "Academic \& Professional Program, Andrew W. Mellon Fellowship in the Department of Textile Conservation at the Metropolitan Museum of Art, New York(2017-2018)" and "Specialized Studies Program from the Department of Heritage Conservation and Restoration, Graduate School of Cultural Heritage, Korea National University of Cultural Heritage(2017)" for the valuable opportunity and experience in New York. We also would like to especially thank the Department head, Janina Poskrobko and every staff members in the Department of Textile Conservation, the Department of Scientific Research, the Department of Paper Conservation, the Department of Asian Art, Antonio Ratti Textile Center, Thomas J. Watson Library and Academic \& Professional Programs at the Metropolitan Museum of Art, New York.

\section{REFERENCES}

Harrison, L.S., 1954, Report on the deterioration effects of modern light sources. The Metropolitan Museum of Art, 1-20. Indictor, N., Koestler, R.J., Blair, C. and Wardwell, A.E., 1988, The evaluation of the metal wrappings from medieval textiles using scanning electron microscopyenergy dispersive X-ray spectrometry. Textile History, 19(1), 3-22.

Indictor, N., Koestler, R.J., Wypyski, M. and Wardwell, A.E., 1989, Metal threads made of proteinaceous substrates examined by scanning electron microscopy-energy dispersive X-ray spectrometry. Studies in Conservation, $34,171-182$.

Jeong, S.H., Yu, J.A., Chung, Y.J. and Sim, Y.O., 2013, Scientific analysis of metal in Chinese and Korean traditional gold thread. Journal of the Korean Society of Clothing and Textiles, 37, 764-771. (in Korean with English abstract)

Muros, V., Wärmländer, S.K., Scott, D.A. and Theile, J.M., 
2007, Characterization of 17 th-19th century metal threads from the Colonial Andes. Journal of the American Institute for Conservation, 46(3), 229-244.

National Research Institute of Cultural Heritage, 2010, Taphonomic studies on the human remains collected from tombs encapsulated by lime soil mixture barrier of Joseon dynasty. 1-29. (in Korean)

National Research Institute of Cultural Heritage, 2011, Taphonomic studies on the human remains collected from tombs encapsulated by lime soil mixture barrier of Joseon dynasty. 1-42. (in Korean)
Nord, A.G. and Tronner, K., 2000, A note on the analysis of gilded metal embroidery threads. Studies in Conservation, 45(4), 274-279.

Tímár-Balázsy, A. and Eastop, D., 1998, Chemical principles in textile conservation. Butterworth Heinemann, Oxford, 128-138.

Yu, J.A., Kim, J.E., Han, Y.B., Lee, S.H. and Chung, Y.J., 2014, Comparative study on characteristic of materials to restore traditional gold threads. Journal of Conservation Science, 30(3), 307-315. (in Korean with English abstract) 